\title{
Editorial: History in anatomy education
}

\author{
F. Duparc ${ }^{1}$ B. Grignon ${ }^{2} \cdot$ D. Kachlik ${ }^{3}$
}

Published online: 17 September 2019

๑) Springer-Verlag France SAS, part of Springer Nature 2019

This issue of Surgical Radiologic Anatomy 2019-10 is especially devoted to different aspects of the history of education in anatomy that can be seen as stories of men, institutions, textbooks, terminology, and recent or new tools.

The first aspect is related to humans, through three examples of great men, contributors in their time to important development of anatomy and clinical knowledge. The second one is a part of history of institutions. The third aspect concerns two important vectors of knowledge these pioneers were able to create and use: the books, mainly, but also some anatomical models. The fourth aspect is related to the terminology as an essential tool for education. The fifth section concerns the evolution of the ways of teaching and learning anatomy, and the importance of the peer guiding for the students. New tools for education are presented and evaluated through three articles in the sixth part and are mainly numeric 3D systems, leading to virtual presentation of anatomy but real learning. The important come back to anatomy in numerous medical and surgical specialties is illustrated in the last section by the development of centers of simulations.

The first section combines the stories of very complete individuals, anatomists, surgeons, but also artists, who were able to constantly research in anatomy the responses to their clinical questions, to teach their personal progress in the clinical anatomy knowledge, and to leave some great heritages to their students. In the eighteenth century, Josias Weitbrecht described the syndesmology, and Václav Trnka created, in Slovakia and Hungary and a great school of anatomy and medicine that showed so actual features of education in anatomy. The example of the depiction of the Poland

F. Duparc

fabrice.duparc@univ-rouen.fr

1 Laboratory of Anatomy, Rouen University, 22 Boulevard Gambetta, 76183 Rouen, France

2 Department of Anatomy, University of Lorraine, Avenue de la Forêt de Haye, 54505 Vandoeuvre-Les-Nancy, France

3 Second Faculty of Medicine, Charles University, V Uvalu 84, 15006 Prague, Czech Republic
Syndrome before Poland illustrates the difficulty of the diffusion of the results of researches in the nineteenth century.

The men would not have been able to build great schools of anatomy without Institutions, with more or less visionary managers; this point remains very actual too. Two examples are proposed, through the celebration of eight centuries of the Montpellier University (France), where Vesalius gave lectures and dissection courses, or five centuries of anatomy teaching in Lyon University (France) in the footsteps of Rabelais, Petit, Lisfranc, Testut and Latarjet, and many others. These famous anatomists and practitioners travelled a lot, between the greatest universities of Europe, and contributed to the exchange of knowledge, but they also used some vectors of publications.

The books were the main supports of the anatomical culture, with paintings and later lithographs that allowed an easier reproduction and faster printing. The example of the old textbook in Turkish language, by Şemseddîn-i Itâkî, written in the seventeenth century, illustrates two important facts in the education of anatomy: the so-called "textbooks" were great literal depictions but associated the huge job of illustrators, and the editions in national languages, useful in the faculties of the concerned countries, showed the difficulties of international diffusion of knowledge and the high necessity of a common terminology. The teaching of anatomy could also use 3D representation of the human body, especially when the dissection could not be allowed, and the "papier mâché anatomical models" were famous and sent in numerous countries, when wax specimens were not available.

The books and the anatomical models were labelled in National Languages. The story of the term "azygos" shows the necessity of a common international terminology, based on comprehensive construction of the terms. The importance of travelling and exchanging the knowledge is once more sustained.

The ways of teaching and learning anatomy have been enlarged by new tools and supports. However, the guiding of the student progression remains very important, as shown by the usefulness of a guidebook in dissection course, and 
the interest of plastinated specimens for a specific visualization of the anatomy but guided by monitors. Learning alone is not the preferred way of the students, and peer-assisted learning supports the place of teachers and monitors. The efficiency and reliability of general databases, as Wikipedia, have been evaluated and showed important limits in the field of musculoskeletal anatomy.

The last article presents the possibilities of applied anatomy in simulation training on perfused human donated bodies to science, which fits the actual evolution of medical learning: "never the first time on patient".

We have mentioned the importance of travelling and meeting anatomists in some other countries, as did the oldest teachers and students. This issue includes the report about the recent congress Anatomia Clinica (Madrid, Spain, June 2019) and the abstracts of the presented oral communications and posters.

We hope you will enjoy reading this issue!

F. Duparc, B. Grignon and D. Kachlik, Editors.

Publisher's Note Springer Nature remains neutral with regard to jurisdictional claims in published maps and institutional affiliations. 